\title{
Other Informatics Shared Resource
}

National Cancer Institute

\section{Source}

National Cancer Institute. Other Informatics Shared Resource. NCI Thesaurus. Code C39487.

Other Informatics Shared Resource provides Cancer Center investigators with types of informatics support that are not listed as provided by other informatics shared resources. 